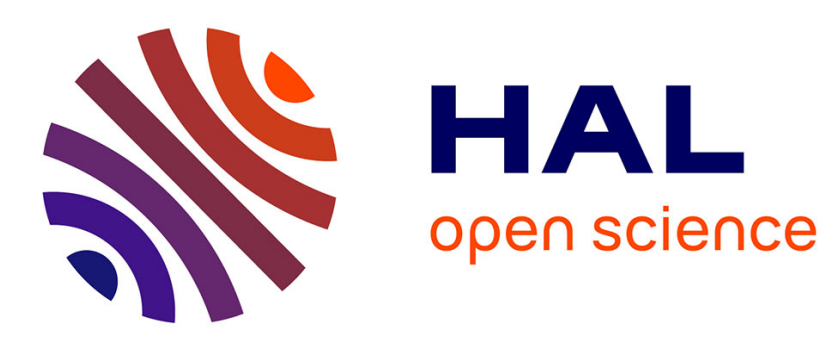

\title{
Short distance correlations in fractal aggregates: numerical simulations and SANS experiments on silica aerogels
}

\author{
A. Hasmy, M. Foret, J. Pelous, R. Jullien
}

\section{- To cite this version:}

A. Hasmy, M. Foret, J. Pelous, R. Jullien. Short distance correlations in fractal aggregates : numerical simulations and SANS experiments on silica aerogels. Journal de Physique IV Proceedings, 1993, 03 (C8), pp.C8-365-C8-368. 10.1051/jp4:1993875 . jpa-00252306

\section{HAL Id: jpa-00252306 https://hal.science/jpa-00252306}

Submitted on 1 Jan 1993

HAL is a multi-disciplinary open access archive for the deposit and dissemination of scientific research documents, whether they are published or not. The documents may come from teaching and research institutions in France or abroad, or from public or private research centers.
L'archive ouverte pluridisciplinaire HAL, est destinée au dépôt et à la diffusion de documents scientifiques de niveau recherche, publiés ou non, émanant des établissements d'enseignement et de recherche français ou étrangers, des laboratoires publics ou privés. 


\title{
Short distance correlations in fractal aggregates: numerical simulations and SANS experiments on silica aerogels
}

\author{
A. HASMY, M. FORET, J. PELOUS and R. JULLIEN \\ Laboratoire de Science des Matériaux Vitreux, Université Montpellier II, Place Eugène Bataillon, \\ 34095 Montpellier cedex 5, France
}

\begin{abstract}
The scattering function $S(q)$ has been computed for simulated fractal aggregates using off-lattice cluster-cluster models. The curve $\log S(q)$ versus $\log q$ goes through a broad minimum followed by damped oscillations at large $q$ values. These simulations are compared with experimental SANS results on colloidal silica aerogels. The agreement between simulations and experiments is qualitatively good.
\end{abstract}

Small Angle Neutron Scattering [SANS] as well as Small Angle X-ray Scattering are now used as a quite common tool[1-2] to determine the fractal dimension of scale-invariant fractal aggregates. The fractal character of the internal structure of an aggregate is characterized by a linear dependence of the logarithm of the scattered intensity $I(q)$ as a function of the logarithm of the modulus $q=\frac{4 \pi}{\lambda} \sin \frac{\theta}{2}$ of the scattering wavevector.

Here, we focus on the large $q$ regime which is related to short interparticle distances within the aggregate. We have built three-dimensional aggregates using several off-lattice hierarchical clustercluster computer algorithms[3]. Then we have calculated the scattering function for an aggregate randomly oriented in space using:

$$
S(q)=\frac{1}{N}\left|\sum_{i=1}^{N} e^{i \vec{q} \cdot \vec{r}_{i}}\right|^{2}=\frac{1}{N} \sum_{i, j} e^{i \vec{q}} \cdot\left(\overrightarrow{r_{i}}-\overrightarrow{r_{j}}\right)=\frac{1}{N} \sum_{i, j} \frac{\sin q r_{i j}}{q r_{i j}}=1+\frac{1}{N} \sum_{i \neq j} \frac{\sin q r_{i j}}{q r_{i j}}
$$

where $N$ is the number of particles, the $\overrightarrow{r_{i}}$ 's refer to the particle centers and $r_{i j}=\left|\overrightarrow{r_{i}}-\overrightarrow{r_{j}}\right|$. Introducing a properly normalized distribution of distances $f(r)$, such that $N 4 \pi r^{2} f(r) d r$ is equal to the number of distances $r_{i j}$ lying between $r$ and $r+d r$, one gets:

$$
S(q)=1+2 \int_{0}^{\infty} \frac{\sin q r}{q} 4 \pi r f(r) d r
$$

The result of the calculation for $f(r)$ is given in figure 1 for aggregates made of $N=4096$ identical particles of unit diameter built according to diffusion limited, ballistic and chemically-limited aggregation models[3]. On this figure one can see a delta-peak at $r=1$ (due to contacting particles) followed by a discontinuity at $r=2$ (due to the contribution of couples of particles in contact with a third one). The corresponding $S(q)$ curves are given in figure 2 . On this figure, one can see the change of slope in the fractal regime due to the influence of the fractal dimension, but, after 
this regime, one sees that the overal shape of $S(q)$, with a broad minimum at $q \simeq 4$ followed by damped oscillations, is quite independent of the aggregation process. This large- $q$ behavior is a direct consequence of the short range features of the $f(r)$ curve, common to all aggregation processes.

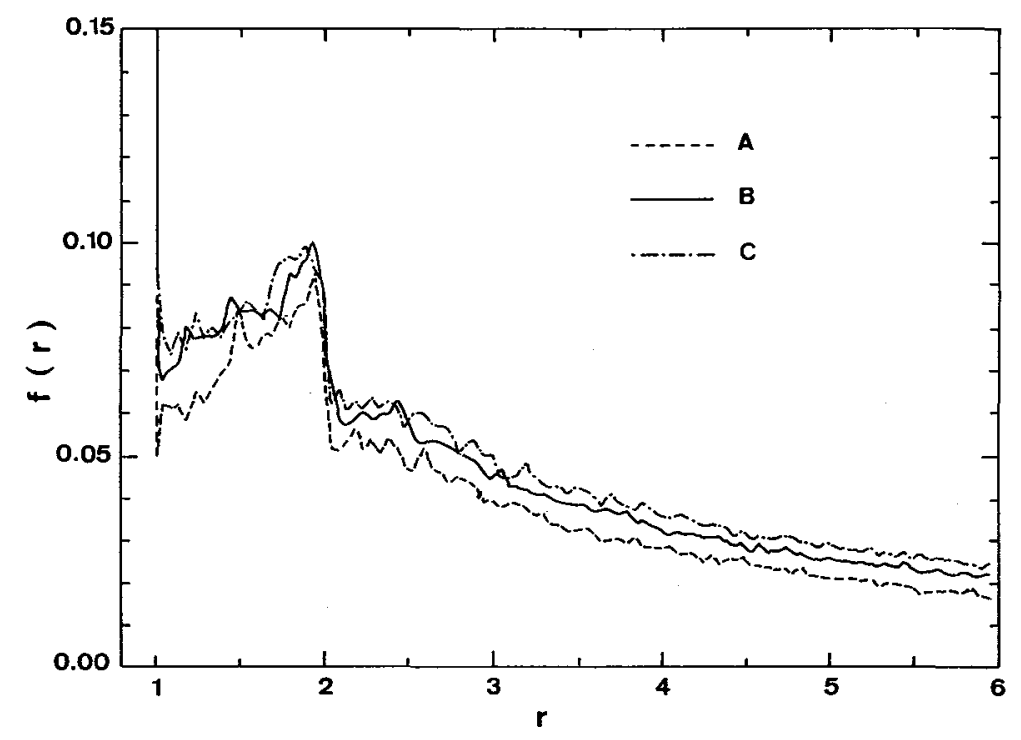

Fig.1.- $f(r)$ curves for diffusion-limited (A), ballistic (B) and chemically-limited (C) aggregates containing $N=4096$ particles.

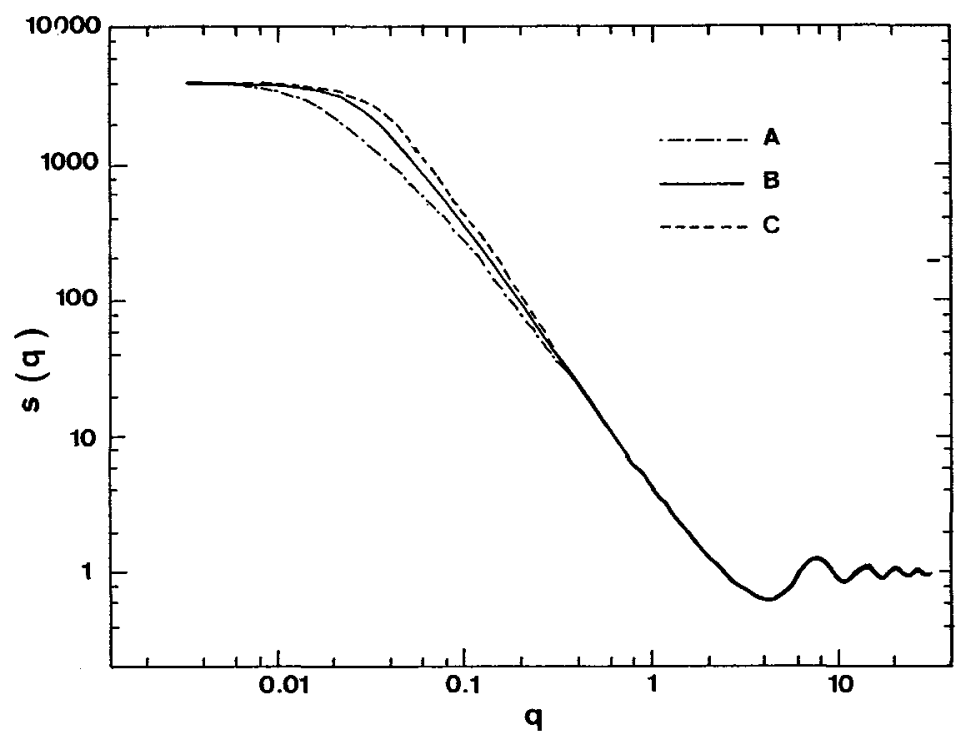

Fig.2. $-S(q)$ curves for diffusion-limited (A), ballistic (B) and chemically-limited (C) aggregates containing $N=4096$ particles. 
These simulations are compared with SANS results on colloidal silica aerogels. The experimental scattering function $S(q)$ is derived from the ratio between the scattered intensity $I(q)$ and the form factor $P(q)$, according to the formula:

$$
I(q)=N S(q) P(q)
$$

where $P(q)$ is the scattering intensity for an homogeneous sphere. In practice, to account for the finite values of the minima of $I(q)$ in the Porod regime, we have considered a small polydispersity of the particle diameters. Consequently we have replaced $P(q)$ by an average $\overline{P(q)}$ over the diameters according to a gaussian probability distribution. The mean particle diameter as well as the standard deviation have been determined in order to obtain the best fit to the intensity curve for the corresponding diluted sol.

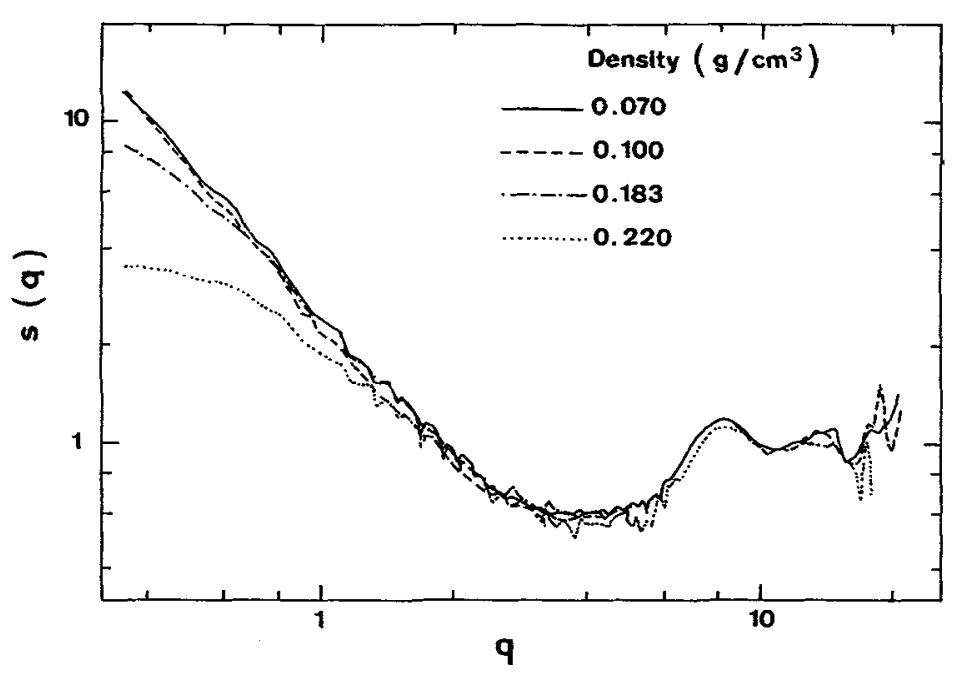

Fig.3.-Experimental $S(q)$ curves for aerogels made of particles of $96 \AA$ diameter. Samples are labelled by their densities.

In figure 3 one gives $\log S(q)$ versus $\log q$ (here $q$ stands for $q a$ where $a$ is the particle diameter) for different aerogels made of particles of the same size $(a=48 \AA)$ but with densities ranging from 0.070 to $0.250 \mathrm{~g} / \mathrm{cm}^{3}$. The curves are all superimposed in the fractal regime as well in the large- $q$ regime where one observes the same characteristic broad minimum followed by damped oscillations as in figure 2. The density fixes the position of the small $q$ saturation which is related to the mean size of the aggregate as expected from formula (1).

In figure 4 we compare two experimental $S(q)$ curves for the same aerogel density $\left(0.10 \mathrm{~g} / \mathrm{cm}^{3}\right)$ with the simulated curve. The agreement between theory and experiment is only qualitative. Even if the data are very noisy for large $q$ values it seems that the large $q$ oscillations of the experimental curves are more damped. This might be accounted for by taking into account indirectly the diameter polydispersity into $S(q)$. But the larger discrepancy occurs at intermediate $q$ values where the minimum is wider and deeper in the experimental curve. Extra numerical simulations[4] done with "restructured" aggregates with a larger coordination number give a deeper but narrower 
minimum. Thus we do not believe the earlier interpretations which were considering anomalously large coordination numbers[2]. One might invoke other possible explanations of this discrepancy, such as the corrections to the simple scattering theory (shadowing, refraction, multiple scattering...) that might occur for large values of the parameter $k a=2 \pi \frac{\alpha}{\lambda}$ (which is here of order 30 to 300 ). This reasonning is supported by the fact that the theoretical curve can be considered as the limit of the experimental ones when $a \rightarrow 0$. The present investigation will be soon completed by a study of the small- $q$ regime based on both experiments and simulations done on a collection of connected aggregates.

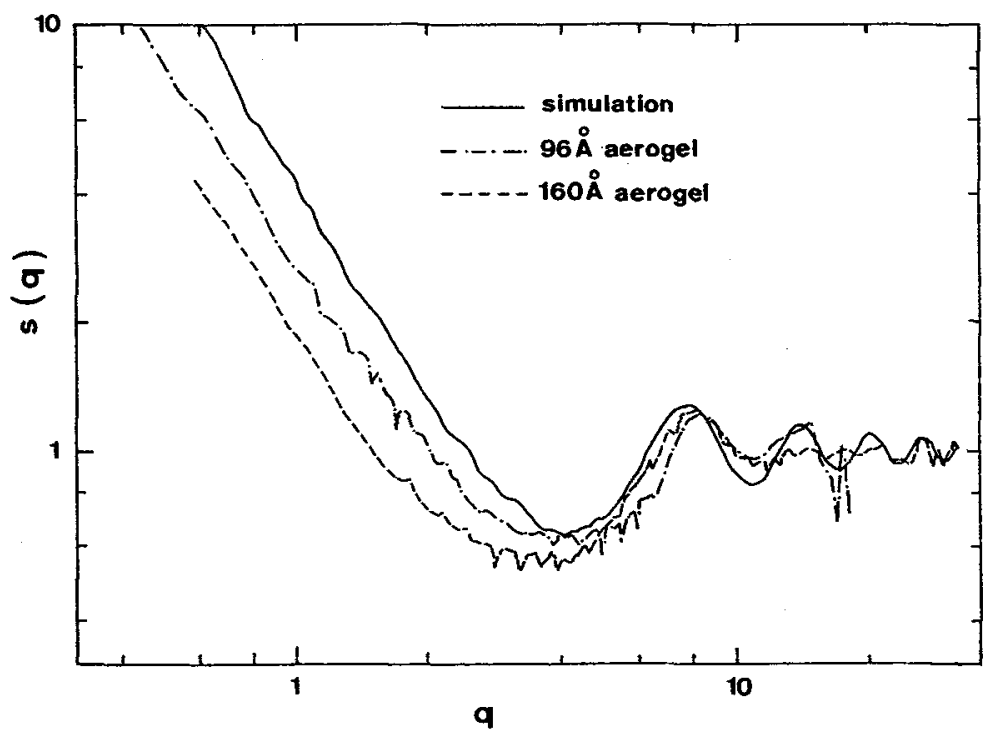

Fig.4.-Experimental $S(q)$ curves for aerogels of various particle diameters but with the same density $\left(\rho=0.10 \mathrm{~g} / \mathrm{cm}^{3}\right)$ and the simulated $S(q)$ curve in the diffusion-limited case.

\section{References}

[1] Schaefer D. W., Martin J. E., Wiltzius P. and Cannell D. S., Phys. Rev. Letters 52 (1984) 2371; Freltoft T., Kjems K. and Sinha S. K., Phys. Rev. B, 33 (1986) 269; Chen S. H. and Teixeira J., Phys. Rev. Letters, 57 (1986) 2583; Cabane B., Dubois M. and Duplessix R., J. de Physique (France), 48 (1987) 2131; Vacher R., Woigner T., Pelous J. and Courtens E., Phys. Rev. B, 37 (1988) 6500; Martin J. E. and Wilcoxon J. P., Phys. Rev. A, 39 (1989) 252.

[2] Dimon P., Sinha S. K., Weitz D. A., Safinya C. R., Smith G., Varady W. A. and Lindsay H. M., Phys. Rev. Letters, 57 (1986) 595; Sinha S. K., Physica D, 38 (1990) 310; Foret M., Pelous J. and Vacher R., J. de Physique I, 2 (1992) 59.

[3] Jullien R. and Botet R., "Aggregation and fractal aggregates", World Scientific (Singapore, 1987).

[4] Hasmy A., Foret M., Pelous J. and Jullien R., preprint. 